\title{
Recurrence of cancer cervix in patients treated by radical hysterectomy followed by adjuvant external beam radiotherapy
}

\author{
Fauzia Sobhan ${ }^{1}$, Farzana Sobhan ${ }^{2}$, Arif Sobhan ${ }^{3}$ \\ ${ }^{I}$ Department of Gynae Oncology, National Institute of Cancer Research \& Hospital (NICR\&H), Mohakhali, \\ Dhaka; ${ }^{2}$ Department of Community Medicine, Bangladesh Medical College, Dhaka; ${ }^{3}$ Epidemic Control \\ Preparedness Unit, ICDDR,B, Mohakhali, Dhaka
}

\begin{abstract}
One hundred and twenty patients with FIGO stage Ib-IIa cervical cancer who had radical hysterectomy prior to January 2003 in different hospitals of Bangladesh and thereafter received external beam pelvic radiotherapy (RT) at National Institute of Cancer Research and Hospital, Dhaka were studied. Until December 2007, 50 (42\%) patients developed recurrence. Thirty-four (70\%) patients experienced local recurrence, $13(26 \%)$ distant recurrence and $2(4 \%)$ both local and distant recurrence. Of 15 patients with distant metastasis, $6(40 \%)$ experienced it in extra-pelvic lymph nodes. The median time to recurrence was 19 months (range 6-120 months) for local failure, 33 months (range 12-108 months) for distant failure and 25 months (range 13-36 months) for those with both local and distant failure. Eighty percent recurrences occurred within 36 months. There was significant correlation between lymph node metastasis and recurrence. All $5(100 \%)$ patients with adenocarcinoma who had positive nodes experienced local recurrence compared with 18 of $49(37 \%)$ squamous cell carcinoma patients with positive nodes. Recurrence more than 5 years after treatment developed in 5 (4\%) patients. Mentionable, $4(80 \%)$ out of 5 patients with late recurrence had squamous cell carcinoma with negative pelvic nodes.
\end{abstract}

\section{Introduction}

Worldwide, cervical cancer is the third most common malignancy and second most common cancer in women ${ }^{1}$. Early stage cervical cancer can be treated by radical hysterectomy or radiotherapy (RT) with similar effectiveness. The choice of treatment depends upon a number of considerations, such as, age of the patient, medical status, experience of the gynaecologist and availability of institutional facilities. When surgery is chosen as the primary therapy, it is supplemented with adjuvant RT if adverse clinicopathological factors are present. These adverse factors are positive lymph nodes, involvement of the parametrium, close or positive surgical margins, and presence of large or deeply invasive tumours. The aim of postoperative RT is to prevent recurrence and improve survival, since recurrence is invariably associated with poor prognosis. The 5year survival rates for early stage cervical cancer treated by radical surgery are in the $80 \%$ to $85 \%$ range; these figures drop to $3.2 \%$ to $13 \%$ when there is recurrence $e^{2-5}$.

Cervical cancer is the leading gynaecological malignancy among females in Bangladesh $^{6}$.
Hospital-based studies show that it constitutes 22$35 \%$ of all female cancers ${ }^{6,7}$. The usual practice in Bangladesh is to do surgery for disease up to stage IIa. However, since most patients present with locally advanced disease and surgery is done by general gynaecologists rather than trained gynaeoncologists, there are concerns regarding the adequacy of surgery performed. A recent study has shown that in Bangladesh, dissection in radical surgery is often not carried out as extensively as is the norm in developed countries of the world. ${ }^{8}$ Pelvic lymphadenectomy - an integral part of radical surgery is incomplete in majority (93\%) of cases and insecure vaginal margins are present in about a third of patients ${ }^{8}$. Considering the ground realities, all surgically treated patients in Bangladesh are considered high-risk and routinely offered adjuvant RT. Whether such an integrated treatment policy is beneficial or not is an issue that has not yet been addressed.

We carried out this study to evaluate the clinical outcome of cervical cancer patients treated by radical hysterectomy and postoperative RT. The endpoints of measurement were the rate and patterns of recurrence. 


\section{Materials \& Methods}

This study was done at Gynae Out Patient Department of National Institute of Cancer Research \& Hospital (NICR\&H) Dhaka from July 2001 to December 2007. Patients who underwent pelvic lymphadenectomy during radical hysterectomy and whose stage at the time of operation was specifically mentioned in the records were included in the study. Patients whose records did not clearly elaborate the extent of surgery done were excluded. Thereafter 120 patients with stage Ib and IIa cervical cancer who had undergone radical hysterectomy in different hospitals/clinics of Bangladesh prior to the year 2003 and subsequently attended NICR\&H for postoperative RT and follow-up were enrolled as the study population. The discharge certificates, operation notes, histopathology reports were studied to obtain the following information: age, stage of cervical cancer, pathological type and grade of tumour, status of removed lymph nodes and excised vaginal margins. All patients received 50c Gy external beam RT to the pelvis at NICR\&H in 25 fractions over a period of 5 weeks. Radiotherapy was commenced within 42 days of surgery and given by Cobalt $^{60}$ machine. Upon completion of RT patients were asked to report for follow-up at 2 months interval in the $1^{\text {st }}$ year, 3 months interval in the $2^{\text {nd }}$ year, 6 months interval in the $3^{\text {rd }}$ year and yearly thereafter. At each visit, thorough clinical examination was done and Pap smear taken. Recurrence when detected was confirmed by biopsy, FNAC (Fine Needle Aspiration Cytology) and imaging studies in relevant cases.

The association between recurrence and prognostic factors was analyzed by chi-square test.

\section{Results}

The median age of the patients was 42 years (range 26-65 years). Median follow-up was 35 months (range 6-144 months). Majority (83\%) of patients presented with stage IIa cervical cancer. Histologically confirmed positive nodes were found in $54(45 \%)$ patients (Table I). Squamous cell carcinoma was the predominant tumour type comprising $91 \%$ of cases. Sixty-five percent of squamous carcinoma and $73 \%$ of adenocarcinoma were moderately differentiated (Table II).

Recurrent cancer was detected in 50 (42\%) patients. Thirty-four $(70 \%)$ patients experienced local recurrence, 13 (26\%) distant metastasis and 2 (4\%) both local and distant recurrence. The median time of recurrence was 19 months (range 6-120 months) for local recurrence, 33 months for distant metastasis (range 12-108 months), and 25 months (range 13-36 months) for those with both local and distant recurrence. Distant recurrences most often involved the lymph nodes, followed by lungs and bones (Table III).

The associations between different prognostic factors and recurrence are shown in Table IV. Amongst the prognostic factors, only lymph node status significantly correlated with recurrence.

Analysis of patterns of recurrence according to cell type and node status shows that local recurrence was twice as common in adenocarcinoma as in squamous cell carcinoma (55\% versus 27\%). All 5 $(100 \%)$ patients with node positive adenocarcinoma suffered local recurrence (Table V).

Among the 50 patients who had recurrence, 10 (20\%) experienced it within the $1^{\text {st }}$ year, $30(66 \%)$ within 2 years, 40 within 3 years (80\%), 44 (88\%) within 4 years, $45(90 \%)$ within 5 years. Of the 5 recurrences that occurred more than five years after completion of treatment, two were evident at the $6^{\text {th }}$ year, and one each at the $8^{\text {th }}, 9^{\text {th }}$ and $10^{\text {th }}$ years. Four of the late recurrence occurred in patients with node-negative squamous cell carcinoma, while one late recurrence was evident in a patient with nodepositive adenocarcinoma.

Table I Clinico-pathologic characteristic

\begin{tabular}{ccc}
\hline Characteristic & Number & Percentage \\
\hline All cases & 120 & \\
Age (years) & 42 & \\
Median (range) & $26-65$ & \\
FIGO stage & 21 & 17.5 \\
Ib & 99 & 82.5 \\
IIa & 54 & 45 \\
Pelvic nodes & 66 & 55 \\
Positive & & \\
Negative & 27 & 40 \\
Vaginal resection margins & 41 & 60 \\
Positive & 52 & \\
Negative & & \\
Not stated $*$ &
\end{tabular}

* 'Not stated' category not included in the calculation of $\%$

Table II: Histotype and grade according to stage of tumor

\begin{tabular}{|c|c|c|c|c|c|}
\hline \multicolumn{6}{|c|}{ Stage Ib $\mathbf{2 1}$} \\
\hline \multicolumn{3}{|c|}{ Squamous Cell Carcinoma $\mathbf{1 8}$} & \multicolumn{3}{|c|}{ Adenocarcinoma $\mathbf{3}$} \\
\hline \multicolumn{3}{|c|}{ Grade } & \multicolumn{3}{|c|}{ Grade } \\
\hline $\mathrm{I}$ & II & III & I & II & III \\
\hline 4 & 11 & 3 & 1 & 1 & 1 \\
\hline \multicolumn{6}{|c|}{ Stage IIa 99} \\
\hline \multicolumn{3}{|c|}{ Squamous Cell Carcinoma 91} & \multicolumn{3}{|c|}{ Adenocarcinoma 8} \\
\hline \multicolumn{3}{|c|}{ Grade } & \multicolumn{3}{|c|}{ Grade } \\
\hline I & II & III & I & II & III \\
\hline 20 & 60 & 11 & 1 & 7 & 0 \\
\hline
\end{tabular}


Table III: Sites of distant metastasis

\begin{tabular}{lc}
\hline Site & No. \\
\hline Lung & 5 \\
\hline Bone & 3 \\
Inguinal nodes & 3 \\
Supraclavicular node & 2 \\
Supraclavicular and axillary nodes & 1 \\
Abdominal wall & 1 \\
\hline Total & 15 \\
\hline
\end{tabular}

Table IV: Association of recurrence with prognostic factors

\begin{tabular}{ccccc}
\hline $\begin{array}{c}\text { Prognostic } \\
\text { Factors }\end{array}$ & $\begin{array}{c}\text { No. of } \\
\text { Recurrence }\end{array}$ & Local & $\begin{array}{c}\text { Site } \\
\text { Distant }\end{array}$ & $\begin{array}{r}\text { Local + } \\
\text { Distant }\end{array}$ \\
\hline $\begin{array}{l}\text { Lymph node status (n) } \\
\text { Positive (54) }\end{array}$ & $31(57 \%)$ & 23 & 7 & 1 \\
Negative (66) & $19(29 \%)$ & 12 & 6 & 1 \\
& $\mathrm{p}<0.01$ & & & \\
Histotype (n) & $43(39 \%)$ & 29 & 12 & 2 \\
Squamous (109) & $7(63 \%)$ & 6 & 1 & 0 \\
Adeno (11) & $\mathrm{p}>0.05$ & & & \\
& & & & \\
Stage (n) & $8(38 \%)$ & 6 & 3 & 0 \\
Ib (21) & $42(42 \%)$ & 29 & 11 & 2 \\
IIa (99) & $\mathrm{p}>0.05$ & & & \\
& & & & \\
\hline
\end{tabular}

Table V: Site of recurrence according to histotype and pelvic node status

\begin{tabular}{lcccc}
\hline & \multicolumn{2}{c}{ Positive nodes } & \multicolumn{2}{c}{ Negative nodes } \\
& $\begin{array}{c}\text { Squamous } \\
(\mathrm{n}=49)\end{array}$ & $\begin{array}{c}\text { Adeno } \\
(\mathrm{n}=5)\end{array}$ & $\begin{array}{c}\text { Squamous } \\
(\mathrm{n}=60)\end{array}$ & $\begin{array}{c}\text { Adeno } \\
(\mathrm{n}=6)\end{array}$ \\
\hline Local & 18 & 5 & 11 & 1 \\
$\begin{array}{l}\text { Distant } \\
\text { Local and }\end{array}$ & 7 & 0 & 5 & 1 \\
Distant & 1 & 0 & 1 & 0 \\
\hline Total & 26 & 5 & 17 & 2 \\
\hline
\end{tabular}

\section{Discussion}

Recurrence rates ranging from $19 \%$ to $36 \%$ have been reported in various series following treatment of cervical cancer by radical surgery and postoperative RT. ${ }^{9,10,11}$ The above recurrence rates were found in study populations with early-stage cervical cancer who had risk factors identified at surgery and consequently received adjuvant RT. The frequency of recurrence in this series is $42 \%$, and it is higher than the above quoted figures. Mentionable, this rate was observed in a heterogeneous study sample comprising both patients with low-risk as well as high-risk factors. It can, therefore, be assumed that most of the surgically treated patients in this series had highrisk clinico-pathological factors, which were either under-reported or else not detected due to inadequate surgery.
Local recurrence rates of $61 \%$ to $74 \%$ have been mentioned in the literature indicating that local relapse accounts for maximal cases of failure in cervical cancer., ${ }^{911,12}$ Over two-thirds of the recurrence in this series are local; this distribution is in accord with the general trend of treatment failure in cervical cancer.

In this series, distant metastasis was more frequently observed in lymph nodes. Some workers have identified the lung as the commonest site of distant failure ${ }^{11,13}$. Whether incomplete pelvic node resection, as is common in radical hysterectomy in Bangladesh, has any bearing on involvement of distant lymph nodes is not certain.

The median time to local recurrence was shorter than that for distant recurrence. Similar observations have been made by other workers ${ }^{9,13,14}$

Metastasis to pelvic lymph nodes is considered to be the dominant prognostic factor in cervical cancer. ${ }^{15}$ In this study, a significantly higher proportion of patients with pelvic node metastasis experienced recurrence than did patients without metastasis. While comprising $45 \%$ of the study population, patients with node metastasis accounted for $68 \%$ of recurrence.

The prognostic relevance of adenocarcinoma is arguable. Some workers have noted higher incidence of lymph node metastasis and increased recurrence rates in adenocarcinoma, while other have not. ${ }^{9}, 12,16,17$ The frequency of recurrence in patients with adenocarcinoma and squamous carcinoma in this series (63\% versus 39\%) is not statistically significant. What is however, noteworthy, is that all $5(100 \%)$ patients with adenocarcinoma who had lymph node metastasis experienced local recurrence compared to $37 \%$ (18 of 49) patients with squamous carcinoma who had positive nodes. This finding reinforces the view that lymph node metastasis portends a worse prognosis for adenocarcinoma than for squamous carcinoma.

In the first year of follow-up after radical hysterectomy, recurrence rates ranging from 35\% to $63 \%$ have been mentioned in various series. 5,13 ,

18 Twenty percent recurrences were diagnosed within the first 12 months in this study. Adjuvant RT given invariably to all patients after surgery probably had a role in delaying the process of recurrence.

There are few published reports on recurrence of cervical cancer more than 5 years after primary therapy. Studies indicate that late recurrence is more common in patients treated by primary radiotherapy than those who had surgery as initial 
treatment ${ }^{19,20}$. Late recurrence rate of cervical cancer in this study is $4 \%$; it is higher than $2.5 \%$ relapse rate mentioned by Takehara et $\mathrm{al}^{20}$. Late recurrence was mostly seen in patients with nodenegative squamous carcinoma. Whether nodenegative patients have a propensity for late recurrence cannot be stated with conclusivity since the number of patients is small. However, the tendency of squamous cell carcinoma to recur after a long period of dormancy has also been noted by other workers ${ }^{20,21}$.

From the available data, it is obvious that quite a large number of cervical cancer patients in Bangladesh have recurrence of the disease after being treated with radical hysterectomy and postoperative RT. Local control is not satisfactory in majority of cases despite adjuvant RT. Several studies have suggested that there is a benefit to cisplatin-based chemotherapy (CT) given either alone or before RT for high-risk surgical patients $^{22-24}$. Peter et al. ${ }^{25}$ carried out a study where high-risk post surgical patients were randomized into two groups-one group receiving concurrent cisplatin-based CT along with RT after radical surgery, and another group receiving only adjuvant RT. Analysis of treatment results showed that there was a $60 \%$ reduction in the rate of local failure and $34 \%$ reduction in distant spread in the group receiving both $\mathrm{CT}$ and $\mathrm{RT}$ compared to the group receiving only pelvic RT after surgery. In Bangladesh, where women will continue to suffer from cervical cancer until sustainable screening programs are initiated, consideration should be given to concurrent chemoradiation in high-risk surgical patients to improve disease control and survival.

\section{References}

1. Garland S M. Human papillomavirus update with a particular focus on cervical disease. Pathology 2002; 34: $213-24$

2. Morley GW, Seski JC. Radical pelvic surgery versus radiation therapy for stage 1 carcinoma of the cervix (exclusive of microinvasion ). Am J Obstet Gynecol 1976; 126: 785-98.

3. Hoskins WJ, Ford JH Jr, Lutz MH, Averette HE. Radical hysterectomy and pelvic lymphadenectomy for the management of early invasive cancer of the cervix. Gynecol Oncol 1976; 4: 278-90.

4. Webb MJ, Symmonds RE. Site of recurrence of cervical cancer after radical hysterectomy. Am J Obstet Gynecol 1980; 138: 813-7.

5. Krebs HB, Helmkamp BF, Sevin BU, Poliakoff SR, Nadji M, Averette HE. Recurrant cancer of the cervix following radical hysterectomy and pelvic node dissection. Obstet Gynecol 1982; 69: 382-5.

6. Mostafa SG, Baki MO, Kader KM. Most common 14 Cancers attended at National Institute of Cancer Research and Hospital (NICRH) from 01.01.1996 to 31.12. 2000 Ban Can reports 2002; 27: 21-26.

7. Akhter PS, Kamaluddin MM, Sharma SK. Patterns of malignant neoplasm - a three year study. Ban Med J 1998; 27 (2): 29-32.

8. Sobhan F, Sobhan F, Sobhan A. Adequacy of Radical Surgery for Cervical Cancer. JOPSOM 2008; 27:10-16.

9. Gadducci A, Fabrini MG, Bonuccelli A, Fanucchi A, Perutelli A, Facchini V. Recurrence patterns in patients with Early Stage Cervical Cancer Treated with Radical Hysterectomy and External Pelvic Irradiation. AntiCancer Res 1995; 15: 1071-78.

10. Atkover G, Uzel O, Ozsahin M, et al. Postoperative radiotherapy in carcinoma of the cervix: treatment results and prognostic factors. Radiother Oncol 1995; 35: 198-205.

11. Tay SK, Tan LK. Outcome of Early Cervical Carcinoma Treated by Wertheim Hysterectomy with selective Postoperative Radiotherapy. Ann Acad Med Singapore 1998; 27: 613-7.

12. Burke TW, Hoskins WJ, Heller PB, Shen MC, Weiser EB, Park RC. Clinical Patterns of Tumour Recurrence After Radical Hysterectomy in Stage 1B Cervical Carcinoma. Obstet Gynecol 1987; 69: 382-85.

13. Wang Chin-Jung, Lai CH, Huang HJ, et al. Recurrent cervical carcinoma after primary radical surgery. Am J Obstet Gynecol 1999; 181: 518-24.

14. Look KY, Rocereto TF. Relapse patterns in FIGO stage 1B carcinoma of the cervix. Gynecol Oncol $1990 ; 38 ; 114-20$

15. Fuller AF Jr, Elliot N, Kosloff C, Hoskins WJ, Lewis JL Jr. Determinants of increased risk for recurrence in patients undergoing radical hysterectomy for stage $1 \mathrm{~B}$ and 11 A carcinoma of the cervix. Gynecol Oncol 1989; 33: 34- 39 .

16. Figgs DC, Tamimi HK. Patterns of recurrence of cervical carcinoma following radical hysterectomy. Am J Obstet Gynecol 1971; 110: 973-78.

17. Chung CK, Nahhas WA, Stryker JA, Curry SL, Abt $\mathrm{AB}$, Mortell R. Analysis of factors contributing to treatment failures in stages $1 \mathrm{~B}$ and $11 \mathrm{~A}$ carcinoma of the cervix. Am J Obstet Gynecol 1980; 138: 550- 56.

18. Dave K, Kapadia A . Retrospective evaluation of recurrence after radical abdominal hysterectomy in patients with cervical carcinoma. Eur J Gynecol Oncol 1990; 1: 67-73.

19. Munnel EW, Bonney WA. Critical points of failure in the therapy of cancer of the cervix. Am J Obstet Gynecol 1961; 81: 521- 34 . 
20. Takehara K, Shigemasa K, Sawasaki T, Naito H, Tuji T. Recurerrence of Invasive Cervical Carcinoma more than 5 years after Initial Therapy. Obstet Gynecol 2001; 98: 680- 4 .

21. Van Herik M, Decker DG, Lee RA, Symmonds RA Late recurrence in carcinoma of the cervix. Am $\mathbf{J}$ Obstet Gynecol 1970; 108: 1183- 6.

22. Wertheim MS, Hakes TB, Daghestani AN, et al. A pilot study of adjuvant therapy in patients with cervical cancer at high risk for recurrence after radical hysterectomy and pelvic lymphadenectomy. J Clin Oncol 1985; 3; 912-16.
23. Lai CH , Lin TS, Soong YK, et al. Adjuvant chemotherapy after radical hysterectomy for cervical carcinoma. Gynecol Oncol 1989; 35; 193-98.

24. Killackey MA, Boardman L, Carrol DS. Adjuvant chemotherapy and radiation in patients with poor prognostic stage IB/IIA cervical cancer. Gynecol Oncol 1993; 49: 377-79.

25. Peters WA III, Liu PY, Barrett RJ, et al. Concurrent Chemotherapy and Pelvic Radiation Therapy Compared with Pelvic Radiation Therapy Alone as Adjuvant Therapy after Radical Surgery in High -Risk Early- Stage Cancer of the cervix. J Clin Oncol 2000; 18; 1606-13. 